\title{
MDMA Elicits Behavioral and Neurochemical Sensitization in Rats
}

\author{
Peter W. Kalivas, Ph.D., Patricia Duffy, B.A., and Susan R. White, Ph.D.
}

Rats were treated with repeated injections of saline or one of two doses of $( \pm) 3,4-m e t h y l e n e d i o x y m e t h a m p h e t a m i n e$ (MDMA; 5 or $20 \mathrm{mg} / \mathrm{kg}, \mathrm{SC})$. Rats pretreated with either of the two repeated MDMA treatment regimens demonstrated an augmented increase in motor activity to an injection of MDMA made 12 days after the last repeated injection compared with either the first MDMA injection or MDMA given to animals pretreated with repeated saline.

Furthermore, animals pretreated with the highest dose of repeated $M D M A$ revealed a greater behavioral response to cocaine (15 mg/kg, IP). Microdialysis was conducted in the nucleus accumbens and the capacity of MDMA $(5 \mathrm{mg} / \mathrm{kg}$, $S C)$ to elevate extracellular dopamine content was augmented in rats pretreated with repeated $M D M A$ compared with the animals pretreated with repeated saline. These data reveal repeated MDMA administration produces behavioral sensitization and enhanced dopamine transmission in the nucleus accumbens of rats.

[Neuropsychopharmacology 18:469-479, 1998]

(C) 1998 American College of Neuropsychopharmacology.

Published by Elsevier Science Inc.
KEY WORDS: MDMA; Nucleus accumbens; Sensitization; Microdialysis; Locomotion; Cocaine

( \pm )3,4-methylenedioxymethamphetamine (MDMA; ecstasy) was initially synthesized in 1914, and subsequent to a short period in the mid-1980s of experimental use as an adjunct in psychotherapy, MDMA became a common recreational drug of abuse (Green et al. 1995). As the popularity of MDMA has increased, psychiatric complications have emerged associated with repeated drug use. Although a diversity of MDMA-associated psychiatric problems have been reported, a frequently identified feature is the induction of anxiety and paranoia, sometimes culminating in panic attacks and paranoid psychosis (McCann and Ricaurte 1991; Creighton et al. 1991; Benzazzi and Mazzoli 1991; Whitaker-Azmitia and Aronson 1989). Although rigorous demographic

From the Alcohol and Drug Abuse Program (PWK, PD), and Department of Veterinary and Comparative Anatomy, Pharmacology, and Physiology (PWK, PD, SRW), Washington State University, Pullman, Washington.

Address correspondence to: Peter Kalivas, Ph.D., Department of VCAPP, Washington State University, Pullman, WA 99164-6520.

Received June 16, 1997; accepted September 26, 1997. analysis of the association between these relatively common psychiatric disorders and repeated MDMA use remains to be conducted (Green et al. 1995), the progressive emergence of anxiety and paranoia is reminiscent of the induction of similar psychopathologies in a subpopulation of methamphetamine and cocaine addicts (Ellinwood 1967; Post 1975; Brady et al. 1991; Satel et al. 1991).

Whereas there is some overlap in the behavioral pharmacology of MDMA and other commonly abused amphetamine derivatives, there also exist clear differences. General overlap can be found in the induction of behavioral excitation (Gold and Koob 1989; Spanos and Yamamoto 1989; Callaway et al. 1991; Callaway and Geyer 1992; McNamara et al. 1995; Dafters 1995) and conditioned place preference (Bilsky et al. 1990; MaronaLewicka et al. 1996). Furthermore, the self-administration of MDMA has been reported in animals first trained to self-administer cocaine (Lamb and Griffiths 1987; Beardsley et al. 1986). Neurochemical overlap is also present because systemic, intracranial, or in vitro administration of MDMA produces a dose-dependent elevation of extracellular serotonin and dopamine in the striatum and nucleus accumbens (Yamamoto and 
Spanos 1988; Fitzgerald and Reid 1990; Gough et al. 1991; Nash and Brodkin 1991; White et al. 1994). In contrast to this general overlap, pharmacological studies reveal a critical involvement of serotonin transmission in the behavioral and neurochemical effects of MDMA (Geyer 1996), but not amphetamine (Cunningham et al. 1992; Seiden et al. 1993). Predominant involvement of serotonin in the effects of MDMA versus amphetamine is revealed by the facts that: (1) the behavioral profile of MDMA differs from that of amphetamine and is markedly attenuated by inhibiting serotonin synthesis and 5-HT $\mathrm{HT}_{1}$ receptors (Callaway et al. 1990, 1992); (2) the increase in dopamine release is partly blocked by inhibiting the serotonin transporter or blocking $5-\mathrm{HT}_{2}$ receptors (Gudelsky and Nash 1996); (3) humans and rats readily distinguish MDMA from amphetamine, and in humans the pattern of abuse differs between MDMA and amphetamine (Geyer 1996; Green et al. 1995; Steele et al. 1994); and (4) repeated MDMA administration produces an enduring depletion of forebrain serotonin in rats and primates that is associated with the selective destruction of fine diameter fibers arising from the dorsal raphe (O'Hearn et al. 1988; Wilson et al. 1989).

Whereas the involvement of serotonin clearly distinguishes the acute effects of MDMA, it is possible that repeated administration of MDMA produces enduring neuroadaptations in the brain that overlap with other commonly abused amphetamines, and may contribute for the induction of paranoia by all drugs in this class (see above). Amphetamine-induced psychopathology has been modeled in rodents as the progressive sensitization of locomotor and stereotyped behavior elicited by repeated drug administration (Segal and Schuckit 1983; Robinson and Becker 1986). A consistent neurochemical feature of enduring behavioral sensitization to amphetamine and cocaine is an increased capacity of these drugs to release dopamine in the nucleus accumbens and striatum (Kolta et al. 1985; Robinson et al. 1988; Pettit et al. 1990; Kalivas and Duffy 1993; Wolf et al. 1993; Paulson and Robinson 1995; Heidbreder et al. 1996). This rat model of psychostimulant psychosis was used to determine whether repeated MDMA administration induces behavioral sensitization and augmented dopamine release in the nucleus accumbens.

\section{METHODS}

\section{Animal Housing and Surgery}

Male Sprague-Dawley rats (Simonsen Laboratories, Gilroy, CA) were housed in groups of four with food and water made available ad libitum. A 12/12-h light/dark cycle was used with the lights on at 6:30 A.M. Rats used for the microdialysis experiment were anesthetized with Equithesin $(3.0 \mathrm{ml} / \mathrm{kg}, \mathrm{IP})$, and a guide cannula (14 mm of 20 ga stainless steel tubing) was stereotaxically implanted 20 ga over the nucleus accumbens $(\mathrm{A} / \mathrm{P}$ $9.0 \mathrm{~mm}$; M/L $1.5 \mathrm{~mm}$; D/V $-0.5 \mathrm{~mm}$; relative to the interaural line) according to the atlas of Pelligrino et al. (1979). The guide cannula was cemented in place by affixing dental acrylic to three stainless steel screws that were tapped into the skull. After surgery the rats were individually housed for the duration of the experiments.

\section{Daily MDMA Treatment and Behavioral Measures}

The treatment regimens used are outlined in Table 1. All rats were placed in the photocell apparatus $24 \mathrm{~h}$ prior to beginning repeated $( \pm) 3,4-M D M A$ (a gift from NIDA) or saline injections (day 1). After a 1-h adapta-

Table 1. Treatment Regimens

\begin{tabular}{|c|c|c|c|c|c|c|c|c|c|c|c|}
\hline Group $^{a}$ & $n$ & Day 1 & Day 2 & Days 3-6 $\mathbf{6}^{b}$ & Day 7 & Day 8 & Day 18 & Day 19 & Day $26^{c}$ & Day $27^{e}$ & Day 34 \\
\hline \multicolumn{12}{|c|}{$\begin{array}{l}\text { Behavioral sensitization } \\
\text { study }\end{array}$} \\
\hline Saline & 9 & Saline & Saline & Saline & Saline & Saline & Saline & MDMA-5 & Saline & Cocaine-15 & Kill \\
\hline MDMA-5 & 7 & Saline & MDMA-5 & MDMA-5 & Saline & MDMA-5 & Saline & MDMA-5 & Saline & Cocaine-15 & Kill \\
\hline MDMA-20 & 8 & Saline & MDMA-5 & MDMA-20 & Saline & MDMA-5 & Saline & MDMA-5 & Saline & Cocaine-15 & Kill \\
\hline \multicolumn{12}{|c|}{ Microdialysis study } \\
\hline Saline & 7 & Saline & Saline & Saline & Saline & Saline & $\begin{array}{l}\text { Saline/ } \\
\text { MDMA-5 } \\
\text { Saline/ }\end{array}$ & & & & \\
\hline MDMA-20 & 6 & Saline & MDMA-5 & MDMA-20 & Saline & MDMA-5 & MDMA-5 & & & & \\
\hline
\end{tabular}

${ }^{a}$ The number after MDMA or cocaine refers to drug dose $(\mathrm{mg} / \mathrm{kg})$.

${ }^{b}$ On days 3-6, injections were made in the home cage of saline or MDMA-20 twice daily at 12-h intervals or of MDMA-5 once a day. All other drug injections were in the test apparatus and given once.

${ }^{c}$ Injections of saline and cocaine on days 26 and 27 were made IP. All other injections were SC.

${ }^{d}$ On day 18 , rats were moved to the microdialysis/photocell chamber and a dialysis probe placed into the nucleus accumbens. On day 19 , the dialysis experiment was conducted and rats were injected with saline SC, followed 80 min later by MDMA SC. 
tion on day 1 , rats were injected with saline $(1.0 \mathrm{ml} / \mathrm{kg}$, SC) and returned to the photocell cage where photocell beam breaks were quantified for $60 \mathrm{~min}$. The next day (day 2), the subjects were divided into two MDMA and a saline treatment group. After the adaptation period, the subjects were administered either saline or MDMA (5 mg/kg, SC), and motor activity was monitored for an additional $2 \mathrm{~h}$. Over the next 4 days (days 3-6), rats were given either saline $(1.0 \mathrm{ml} / \mathrm{kg}, \mathrm{SC}$, twice daily) or a low $(5 \mathrm{mg} / \mathrm{kg}$, SC, once daily) or high $(20 \mathrm{mg} / \mathrm{kg}$, SC, twice daily) MDMA treatment regimen in the home cage. One day after the last repeated injection (day 7), the rats were adapted to the photocell boxes for $60 \mathrm{~min}$, followed by an injection of saline and motor activity was quantified for an additional $60 \mathrm{~min}$. The next day (day 8 ), the rats were again adapted to the photocell cage for $60 \mathrm{~min}$ and the rats pretreated with saline were injected with saline, whereas both of the MDMA pretreatment groups were injected with MDMA $(5 \mathrm{mg} / \mathrm{kg}$, SC). Motor activity was monitored for an additional 120 min after the saline or MDMA injection.

Eleven days after the last injection of MDMA or saline (day 18), rats were returned to the photocell chamber. After a 60-min adaptation, the rats were administered saline and motor activity was monitored for 60 min. The next day (day 19), the rats were returned to the photocell cage and all animals were administered MDMA (5 mg/kg, SC). Seven days later (day 26), the rats were again adapted to the photocell cage for $60 \mathrm{~min}$ then administered saline $(1 \mathrm{ml} / \mathrm{kg}, \mathrm{IP})$. The next day (day 27), after a 60-min adaptation, all animals were administered cocaine $(15 \mathrm{mg} / \mathrm{kg}$, IP) and photocell counts monitored for an additional $120 \mathrm{~min}$. On day 34, the rats were decapitated and brain tissue harvested for measurement of monoamines (see below).

The photocell apparatus used consisted of 16 photocell cages (Omnitech Inc., Columbus, $\mathrm{OH}$ ), each located in a separate sound attenuated chamber with individual light and air sources. Each apparatus contained 16 infrared photocells located $2 \mathrm{~cm}$ off the cage floor to measure horizontal activity (e.g., a combination of locomotion and stereotypy) and 8 photocells located $6 \mathrm{~cm}$ off the floor to estimate vertical activity (e.g., rearing).

Microdialysis. The dialysis probes were constructed as described by Robinson and Wishaw (1988), with 2.0 to $2.5 \mathrm{~mm}$ of active dialysis membrane exposed at the tip. The probes were inserted through the guide cannula into the nucleus accumbens the night prior to the experiment. The next day, dialysis buffer $(2.7 \mathrm{mmol} / \mathrm{L} \mathrm{KCl}, 140$ $\mathrm{mmol} / \mathrm{L} \mathrm{NaCl}, 1.2 \mathrm{mmol} / \mathrm{L} \mathrm{CaCl}, 1.2 \mathrm{mmol} / \mathrm{L} \mathrm{MgCl}$, $5.0 \mathrm{mmol} / \mathrm{L}$ d-glucose, plus $0.2 \mathrm{mmol} / \mathrm{L}$ phosphatebuffered saline to give a $\mathrm{pH}$ value of 7.4 and a final sodium concentration of $140.7 \mathrm{mmol} / \mathrm{L}$ ) was advanced through the probe at a rate of $1.9 \mathrm{ml} / \mathrm{min}$ via a syringe pump (Harvard Instruments, Boston, MA) for $2 \mathrm{~h}$.
Rats were treated on days 1 through 8 as described above (See Table 1) with repeated saline or MDMA (20 $\mathrm{mg} / \mathrm{kg}, \mathrm{SC}$ ), and 11 days later (day 18) a microdialysis probe was inserted through the guide cannula into the nucleus accumbens. Approximately $16 \mathrm{~h}$ later (day 19), 20-min baseline samples were collected for $100 \mathrm{~min}$, followed by an injection of saline $(1.0 \mathrm{ml} / \mathrm{kg}, \mathrm{SC})$ and 80 min later by an injection of MDMA ( $5 \mathrm{mg} / \mathrm{kg}$, SC). During both baseline and drug administration, samples were taken every $20 \mathrm{~min}$, and the experiment was conducted in a photocell cage to permit the simultaneous monitoring of motor activity (Omnitech Electronics, Columbus, $\mathrm{OH}$ ). At the end of the experiment, the dialysis probe was removed, and the animal was administered an overdose of pentobarbital ( $>100 \mathrm{mg} / \mathrm{kg}$, IP).

Measurement of Monoamines. The dialysis samples were collected into microfuge tubes in $20 \mu$ l of mobile phase $\left(0.1 \mathrm{~mol} / \mathrm{L}\right.$ citric acid, $75 \mathrm{mmol} / \mathrm{L} \mathrm{Na}_{2} \mathrm{HPO}_{4}, 0.6-$ $1.0 \mathrm{mmol} / \mathrm{L}$ heptane sulfonic acid, $0.1 \mathrm{mmol} / \mathrm{L}$ EDTA, $13 \%$ methanol, $\mathrm{V} / \mathrm{V}, \mathrm{pH}=3.8-4.2$ ) plus 2.0 pmol dihdroxybenzylamine as the internal standard, and placed in a freezer $\left(-70^{\circ} \mathrm{C}\right)$ until analyzed for dopamine content. The samples were placed in a refrigerated autosampler (Gilson Medical Supplies, Middleton, WI) and dopamine content measured using high-performance liquid chromatography (HPLC) with electrochemical detection. The dopamine was separated using a $25 \mathrm{~cm} \mathrm{C}-18$ reversed-phase column (Bioanalytical Systems, West Lafayette, IN) and oxidized/reduced using coulometric detection (ESA Inc., Bedford, MA). Three electrodes were used: a pre-injection port guard cell $(0.4 \mathrm{~V})$ to oxidize the mobile phase, an oxidation analytical electrode $(0.3 \mathrm{~V})$, and a reduction analytical electrode $(-0.2 \mathrm{~V})$. Peaks were recorded on a chart recorder and compared to an external standard curve (10 to $1000 \mathrm{fmol})$.

Tissue levels of monoamines were determined using HPLC with electrochemical detection. One week after the final cocaine injection (day 34), the rats were decapitated and the prefrontal cortex, core and shell of the nucleus accumbens, and dorsolateral striatum were dissected on an ice-cooled glass plate. A coronal slab of tissue was obtained by dropping a razor blade $0.5 \mathrm{~mm}$ rostral to the olfactory tubercle and making a parallel cut $1.5 \mathrm{~mm}$ caudal. The prefrontal cortex was hand dissected (Deutch et al. 1985), and the other brain regions obtained using a 16-gauge punch. Immediately after dissection, bilateral tissue pieces were placed in $0.5 \mathrm{ml}$ of mobile phase $(0.1 \mathrm{~mol} / \mathrm{L}$ trichloroacetic acid, $0.01 \mathrm{~mol} / \mathrm{L}$ sodium acetate, 0.1 moltc/L EDTA and $18 \%$ methanol, $\mathrm{pH}=3.85)$ containing $2 \times 10^{-7} \mathrm{~mol} / \mathrm{L}$ isoproterenol as an internal standard, sonicated and centrifuged $(13,000 \times g)$ for $2 \mathrm{~min}$. The resulting pellet was assayed for protein content using Folin reagent, and 50 to $150 \mu \mathrm{l}$ of the supernatant injected into an HPLC system. The monoamines were separated using an ODS C-18 re- 
versed-phase column (Bioanalytical, Lafayette, IN) and detected at $0.7 \mathrm{~V}$ by a glassy carbon electrode. Peak height was measured against a standard curve (1 to 100 pmol), and the final data expressed as pmol per $\mathrm{mg}$ protein.

Histology and Statistics. Rats used for microdialysis were perfused intracardially with phosphate-buffered saline $(60 \mathrm{ml})$ followed by $10 \%$ formalin $(60 \mathrm{ml})$. The brains were removed, stored in $10 \%$ formalin for at least 1 week, and coronal sections ( $100 \mu \mathrm{m}$ thick) were taken at the level of the nucleus accumbens with a vibratome. The sections were mounted on gelatin-coated slides and stained with Cresyl violet. Probe placements were determined according to the atlas of Paxinos and Watson (1986) by an individual unaware of the rats' neurochemical response. The data were evaluated using a one- or two-way ANOVA. Post hoc comparisons between multiple groups were made using a least significant difference test described by Milliken and Johnson (1984), and multiple comparisons to a single treatment were made using a Dunnett's test.

\section{RESULTS}

\section{Behavioral Sensitization to Repeated MDMA Administration}

Figure 1 shows that acute injection of MDMA $(5.0 \mathrm{mg} / \mathrm{kg}$, SC) on day 2 produces an increase in horizontal photocell counts, distance traveled, and stereotypy counts compared with the saline injection made on day 1 . In contrast, there was no statistically consistent increase in vertical photocell counts after acute MDMA administration (data not shown).

The motor stimulant effect of MDMA $(5.0 \mathrm{mg} / \mathrm{kg}$, SC) was significantly augmented after repeated treatments with either 5.0 or $20.0 \mathrm{mg} / \mathrm{kg}$, SC, of MDMA for 4 days. At 11 days after the last repeated injection of MDMA or saline (day 19), MDMA-induced elevations in horizontal photocell counts, distance traveled, and stereotypy were greater in the two MDMA pretreatment groups than in the saline-pretreated groups. Similarly, the response to MDMA on day 19 was greater than the effect of the first MDMA injection made on day 2. In contrast, when MDMA was administered $48 \mathrm{hr}$ after discontinuing repeated treatments (day 8 ), the behavioral stimulant effect was significantly greater than the first MDMA administration (day 2) only in the group pretreated with daily injections of $5.0 \mathrm{mg} / \mathrm{kg}$ of MDMA. The augmentation was manifest in horizontal photocell counts and distance traveled, but not in the measure of stereotypy.

The time course data for horizontal photocell counts after MDMA administration on day 19 is also shown in Figure. 1. MDMA produced more photocell counts in both MDMA pretreatment groups between 30 and 90 min after injection compared with the effect in the saline-pretreated group. At no time after injection did the response to MDMA differ between the two MDMA pretreatment groups.

Figure 2 shows that cross-sensitization with the motor stimulant effect of cocaine $(15 \mathrm{mg} / \mathrm{kg}$, IP) was produced in rats pretreated with repeated injections of $20.0 \mathrm{mg} / \mathrm{kg}$, SC of MDMA, but not in the group pretreated with the lower dose of MDMA. The cross-sensitization was apparent for both horizontal activity and distance traveled, whereas the effect of cocaine on stereotypy was not significantly different between the MDMA and saline pretreatment groups. The time course data for cocaineinduced horizontal photocell counts reveals that the augmented response occurred during the first $30 \mathrm{~min}$ after cocaine administration.

\section{Neurochemical Sensitization to Repeated MDMA Administration}

Microdialysis was used to measure the extracellular content of dopamine in the nucleus accumbens at 2 weeks after discontinuing repeated MDMA injections $(20 \mathrm{mg} / \mathrm{kg}$, SC, b.i.d.). Neither the basal level of extracellular dopamine nor horizontal photocell counts differed between the repeated MDMA and saline pretreatment groups (Figure 3). Likewise, neither the behavioral or neurochemical effects of acute saline administration $(1.0 \mathrm{ml} / \mathrm{kg}, \mathrm{SC})$ were distinguished between the two pretreatment groups. An acute injection of MDMA (5.0 $\mathrm{mg} / \mathrm{kg}, \mathrm{SC}$ ) significantly increased motor activity in both groups, with the response in the MDMA pretreatment group being significantly greater than the control group between 60 and 120 min after injection. Similarly, the increase in extracellular dopamine by MDMA was greater in the nucleus accumbens of rats pretreated with repeated MDMA injections between 40 and 120 min after acute MDMA administration.

Figure 4 shows the location of microdialysis probes within the nucleus accumbens of the animals used in the data shown in Figure 3. The probes were primarily in the medial core of the rostral half of the nucleus accumbens. However, portions of the active regions of the probes were variably located dorsal or ventral to the core in the ventral striatum or lateral limb of the shell of the nucleus accumbens, respectively.

\section{Effect of Repeated MDMA on Monamine Tissue Levels}

Table 2 shows the tissue levels of dopamine, serotonin, and norepinephrine in the brains of the rats 1 or 2 weeks after completing the experiments shown in Figure 1 and Figure 2 . The highest daily dosing regimen of MDMA produced a significant reduction in the level of 

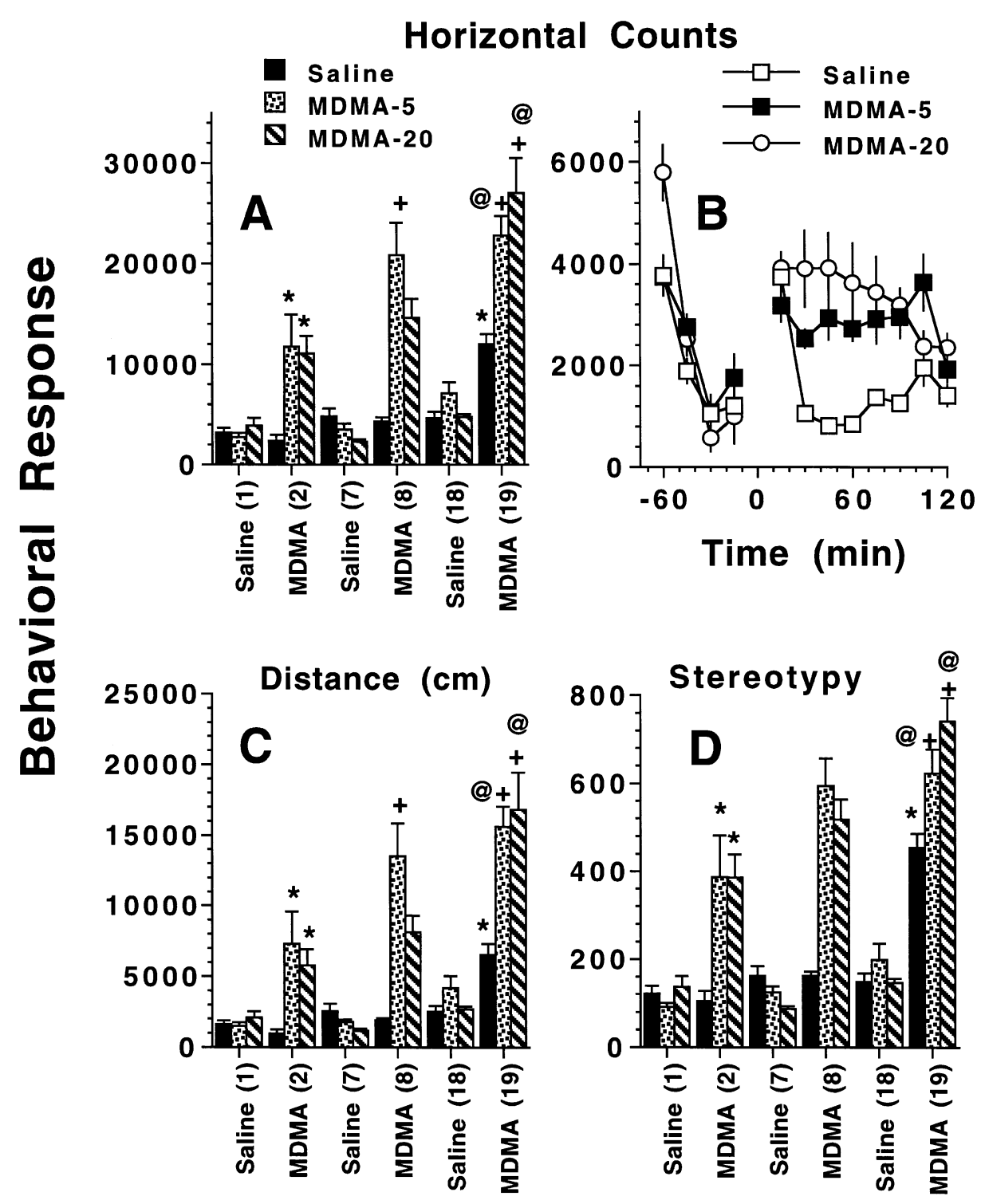

Figure 1. Effect of repeated MDMA on saline- and MDMA-induced motor activity. Rats were injected with saline (1 ml/ $\mathrm{kg}$, SC) or MDMA (5 mg/kg, SC) on the days indicated in parentheses (see Table 1). On days 3-6, subjects received injections of saline or 5 or $20 \mathrm{mg} / \mathrm{kg}$, SC, of MDMA (MDMA- 5 or MDMA-20). The bar graphs in panels A, C, and D illustrate the mean \pm SEM total photocell counts, distance traveled $(\mathrm{cm})$, and stereotypy over the $120 \mathrm{~min}$ after injecting saline or MDMA. The line graph in panel B shows the time course of horizontal photocell counts during the adaptation period and during the 120 min after injecting MDMA on day 19. The data were statistically evaluated using a two-way ANOVA with repeated measures over day of injection or time (Panel B). Panel A: treatmentF(2,17) =9.03, $p=.002$; dayF $(7,119)=74.00, p<.001$; interactionF $(14,119)=4.52, p<.001$. Panel B: treatmentF $(2,17)=7.96, p=.004 ; \operatorname{timeF}(11,187)=19.43, p<.001 ;$ interactionF $(22,187)=$ $3.739, p<.001$. Panel C: treatmentF $(2,17)=7.60, p=.004 ; \operatorname{dayF}(7,119)=63.50, p<.001 ; \operatorname{interactionF}(14,119=4.01, p<.001$. Panel D: treatmentF $(2,17)=9.15, p=.002 ; \operatorname{dayF}(7,119)=105.43, p<.001 ;$ interactionF $(14,119)=6.84, p<.001$. ${ }^{*} p<.05, \operatorname{com}-$ pared with saline (1) within each treatment group, using a least significant difference test (Milliken and Johnson 1984). $+p<$ .05 , compared with MDMA (2) within each treatment group. @ $p<.05$, compared with the b.i.d. saline group on day 19.

serotonin in all brain nuclei examined, including the prefrontal cortex, shell and core of the nucleus accumbens, and the dorsalateral striatum. A depletion in serotonin was not elicited in any brain region by pretreatment with the lower dose of MDMA. In contrast, in the low dose MDMA group, the level of serotonin was ele- vated in the prefrontal cortex and shell of the nucleus accumbens. Similarly, the levels of extracellular dopamine were significantly elevated in the shell and core of the nucleus accumbens by the low dose regimen of MDMA. The level of dopamine was also increased in the core after b.i.d. injections of the highest dose of 


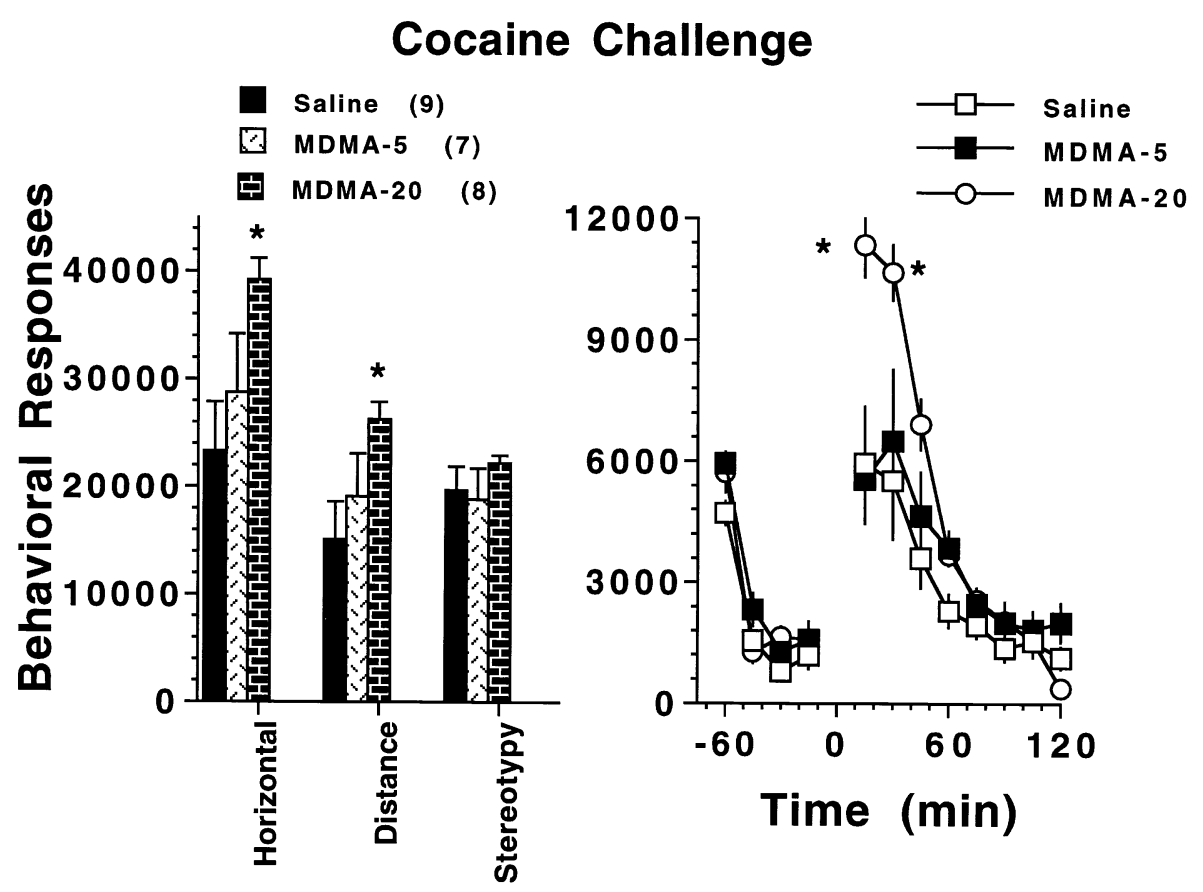

Figure 2. Cross-sensitization between repeated MDMA and cocaine. All rats used in the data shown in Figure 1 were administered cocaine $(15 \mathrm{mg} / \mathrm{kg}$, IP) 1 week after the last injection of MDMA (i.e., on day 27). The bar graph illustrates the mean \pm SEM total photocell counts, distance traveled $(\mathrm{cm})$, and stereotypy counts over the 120 min after injecting cocaine. The stereotypy counts were multiplied by 30 to permit illustration on the same scale as horizontal photocell counts and distance traveled. The line graph shows the time course of horizontal photocell counts during the adaptation period and the 120 min after injecting cocaine. The data were statistically evaluated using a one-way ANOVA for total behavior and a two-way ANOVA with repeated measures over time for the time course data. Total Behavior: horizontalF $(2,21)=3.79, p=.039, \operatorname{dis}-$ tanceF $(2,21)=3.42, p=.052 ;$ stereotypyF $(2,21)=.79, p=.466$. Timecourse: treatmentF $(2,17)=4.34, p=.027 ;$ timeF $(11,187)=$ $58.38, p<.001$; interactionF $(22,187)=4.983, p<.001,{ }^{*} p<.05$ comparing saline with MDMA-5 or MDMA-20 using a Dunnett's test for the total behavioral data and a least significant difference test for the time course data.

MDMA. No alteration was measured in the levels of norepinephrine in either the prefrontal cortex or shell.

\section{DISCUSSION}

This study demonstrates that, akin to other commonly abused amphetamine derivatives and cocaine (Robinson and Becker 1986; Kalivas and Stewart 1991), repeated administration of MDMA produces sensitization to the behavioral stimulant effects of an acute MDMA challenge. Also similar to other amphetamines (Robinson et al. 1988; Akimoto et al. 1990), the augmented behavioral response was accompanied by an increased capacity of MDMA to elevate extracellular dopamine content in the nucleus accumbens. The concordance between MDMA and other amphetamine derivatives and cocaine regarding the induction of behavioral and neurochemical sensitization in a rat model of amphetamine psychosis supports a hypothesis that the emergence of anxiety and psychosis associated with abuse of these drugs may arise, in part, from similar neuroadaptations. This possibility is further buttressed by the demonstration of behavioral cross-sensitization between MDMA and cocaine.

\section{Behavioral Sensitization to MDMA}

Although the automated measures of locomotion and stereotypy were augmented by repeated MDMA treatment, it is important to note that these methods do not provide detailed characterization of the behavioral profile. Indeed, the profile of augmented behaviors to other amphetamine-like stimulants depends upon which drug is used, the dose used, and reveals a high degree of individual variability (Segal and Kuczenski 1987; Kalivas et al. 1988). Thus, detailed rating of behavior would likely reveal distinctions between MDMAinduced behavioral sensitization and that elicited by repeated administration of other amphetamine-like drugs.

Although consistent with two previous reports (Spanos and Yamamoto 1989; Dafters 1995), the development of behavioral sensitization after repeated MDMA administration was not observed in three studies (Gold 


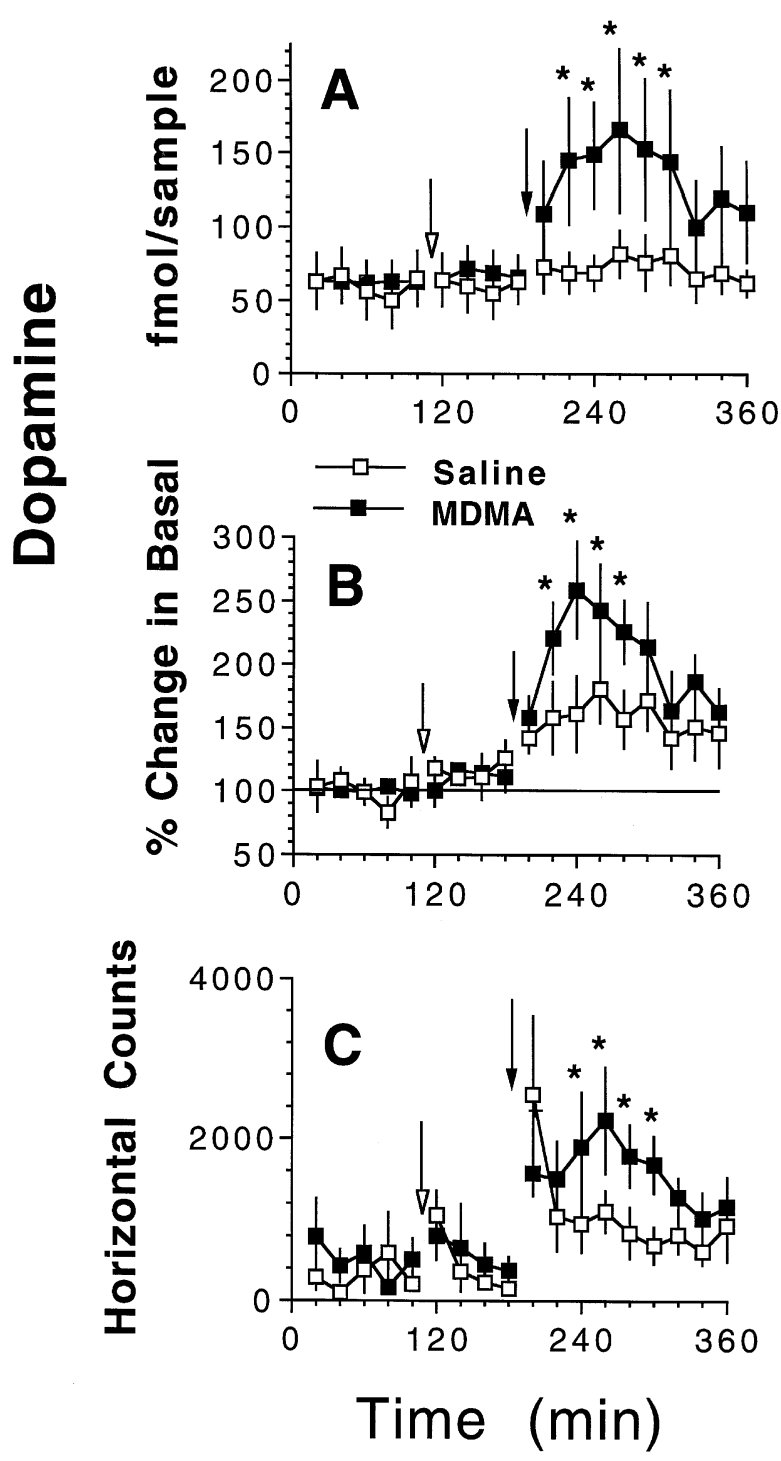

Figure 3. Augmented increase in extracellular dopamine content in the nucleus accumbens of MDMA-sensitized subjects. Rats were pretreated with repeated saline $(n=7)$ or MDMA $(n=6 ; 20 \mathrm{mg} / \mathrm{kg}, \mathrm{SC})$ as described in the legend for Figure 1. Twelve days later, dialysis was conducted in the nucleus accumbens. Following five baseline samples, saline (open arrow; $1 \mathrm{ml} / \mathrm{kg}$, SC) was administered and 80 min later MDMA was injected (closed arrow; $5 \mathrm{mg} / \mathrm{kg}$, SC). Panel A shows the raw mean \pm SEM extracellular dopamine levels (uncorrected for probe recovery), panel B shows the data in panel A normalized to the percent change from the average of the five baseline samples, and panel $C$ shows the mean \pm SEM horizontal photocell counts obtained simultaneously with the dialysis samples. The data were statistically evaluated using a two-way ANOVA with repeated measures over time. Panel A: treatmentF $(1,11)=1.18, p=.301 ; \operatorname{timeF}(15$, $165)=6.18, p<.001$; interactionF $(15,165)=2.58, p=.002$. Panel B: treatmentF $(1,11)=1.66, p .225 ; \operatorname{timeF}(15,165)=$ 12.36, $p<.001$; interactionF $(15,165)=1.98, p=.020$. Panel C: treatmentF $(1,11)=.80, p=.390 ; \operatorname{timeF}(15,165)=6.37, p<$ .001 ; interaction $\mathrm{F}(15,165)=1.69, p=.058 .{ }^{*} p<.05$, comparing saline with MDMA at individual times, using a least significant difference test (Milliken and Johnson 1984).

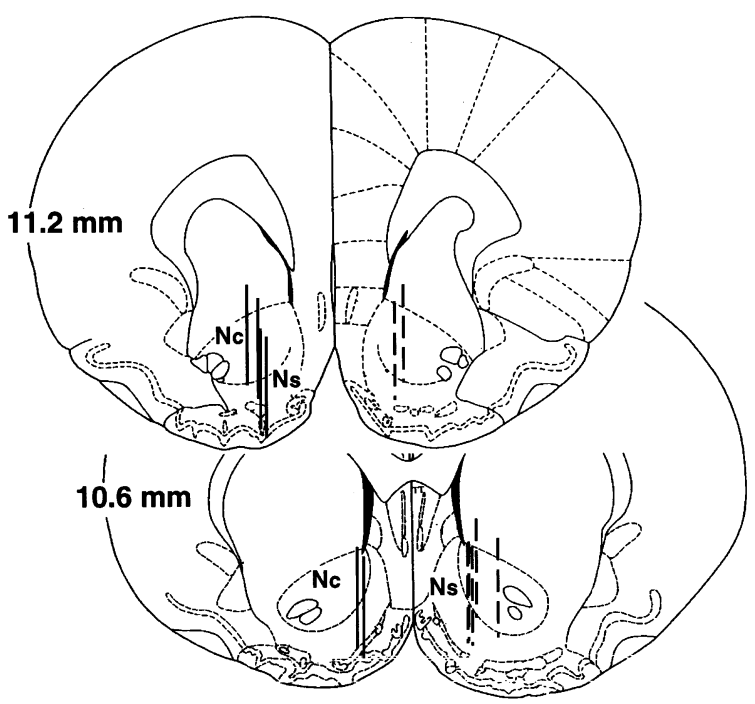

Figure 4. Location of dialysis probes in the nucleus accumbens from animals used in the data shown in Figure 3. The solid lines on the left refer to probe location in the rats pretreated with repeated MDMA injections $(n=6)$, and the dashed lines on the right indicate the location of probes in the repeated saline treatment group $(n=7)$. The numbers indicated $\mathrm{mm}$ rostral to interaural zero in the atlas of Paxinos and Watson (1986). Nc = core of the nucleus accumbens; Ns = shell of the nucleus accumbens.

and Koob 1989; Callaway and Geyer 1992; McNamara et al. 1995). There are two distinctions between these studies that may have contributed to the different results. First, many studies have shown that behavioral sensitization to amphetamine derivatives and cocaine is most robust if animals are tested following an extended withdrawal period after discontinuing repeated drug administration (Kolta et al. 1985; Antelman 1988; Kalivas and Duffy 1993; Heidbreder et al. 1996). The delayed sensitization is amplified if higher dose or more frequent repeated drug injections are made (Paulson et al. 1991; Kalivas and Duffy 1993; Paulson and Robinson 1995). These time and dose relationships are reflected in the present study where at $48 \mathrm{~h}$ after discontinuing repeated MDMA treatment there was no behavioral sensitization in the group pretreated with the highest repeated MDMA regimen, but the group treated with the lower dosage regimen showed significantly enhanced behavioral activity. Furthermore, after 11 days of withdrawal from the repeated MDMA injections, all treatment groups demonstrated robust behavioral sensitization to a MDMA challenge. Two of the three previous studies that did not reveal behavioral sensitization to repeated MDMA examined animals only at $24 \mathrm{~h}$ after discontinuing the repeated treatment regimen (Gold and Koob 1989; McNamara et al. 1995). However, the study by Callaway and Geyer (1992) evaluated animals at both $36 \mathrm{~h}$ and 21 days after the last repeated MDMA injection and observed tolerance and no alteration, re- 
Table 2. Effect of Repeated MDMA Treatment on the Levels of Monoamines in the Brain

\begin{tabular}{llccc}
\hline \multirow{2}{*}{ Brain Nucleus } & $\begin{array}{c}\text { Repeated } \\
\text { Treatment }\end{array}$ & Serotonin & Dopamine & Norepinephrine \\
\cline { 3 - 5 } & Saline & $25.8 \pm 1.7$ & $3.9 \pm 0.2$ & $13.0 \pm 0.5$ \\
Prefrontal cortex & 5.0 MDMA & $32.1 \pm 0.9^{a}$ & $4.5 \pm 0.2$ & $14.7 \pm 0.7$ \\
& 20.0 MDMA & $12.7 \pm 1.1^{a}$ & $3.8 \pm 0.3$ & $12.5 \pm 0.6$ \\
NA shell & Saline & $38.6 \pm 2.6$ & $277 \pm 11$ & $21.5 \pm 1.9$ \\
& 5.0 MDMA & $46.8 \pm 2.8^{a}$ & $332 \pm 7^{a}$ & $28.5 \pm 2.8$ \\
NA core & 20.0 MDMA & $22.6 \pm 1.8^{a}$ & $289 \pm 8$ & $30.5 \pm 4.1$ \\
& Saline & $20.2 \pm 0.8$ & $291 \pm 21$ & ND \\
Striatum & 5.0 MDMA & $21.5 \pm 0.7$ & $351 \pm 18^{a}$ & ND \\
& 20.0 MDMA & $11.2 \pm 0.8^{a}$ & $354 \pm 13^{a}$ & ND \\
& Saline & $10.6 \pm 0.5$ & $517 \pm 16$ & ND \\
& 5.0 MDMA & $10.4 \pm 1.0$ & $518 \pm 31$ & ND \\
\hline
\end{tabular}

Rats were administered daily saline $(n=9)$, MDMA $5.0 \mathrm{mg} / \mathrm{kg}$, IP $(n=7)$ or $20 \mathrm{mg} / \mathrm{kg}$, IP MDMA $(n=8)$, as described in experiment \#1. Following the behavioral studies in experiment \#1, the rats were decapitated. $\mathrm{ND}=$ not detected

${ }^{a} p<.05$ comparing MDMA treatment groups with saline, using a one-way ANOVA followed by a Dunnett's test.

spectively, in the motor response to an acute MDMA injection. It is possible that the behavioral sensitization we observed at 11 days after the last daily MDMA injection may dissipate by 21 days. However, this seems unlikely because behavioral cross-sensitization to cocaine was observed at 19 days after discontinuing daily MDMA.

A second explanation may be related to the fact that learned associations made between the injection of amphetamine derivatives and environmental stimuli increase the expression of behavioral sensitization (Stewart and Vezina 1988). In the Callaway and Geyer (1992) study, all repeated injections of MDMA were made in an environment distinct from the test environment. In contrast, in studies showing behavioral sensitization to MDMA the animals had at least one previous exposure to MDMA in the test apparatus prior to evaluating the behavioral response to MDMA after discontinuing the repeated treatments (Spanos and Yamamoto 1989; Dafters 1995). Supporting a hypothesis that learned associations may be important in the expression of sensitization to MDMA, Gold and Koob (1989) observed that daily administration of MDMA in the test environment resulted in the production of conditioned locomotor activity to a subsequent saline injection.

The fact that behavioral augmentation was present in rats sustaining partial serotonin depletions, as well as in rats treated with a MDMA dosage regimen that was not neurotoxic indicates that serotonin depletion is not necessary for the induction of behavioral sensitization. Interestingly, both groups of rats pretreated with repeated MDMA injections showed an increase in the tissue content of dopamine in the nucleus accumbens (see Table 2). Similar increases in dopamine tissue content have been reported previously (McNamara et al. 1995) and may contribute to the augmented increase in extracellular dopamine seen in the nucleus accumbens in response to an acute MDMA injection (see below).

\section{Neurochemical Sensitization to MDMA}

Previous in vivo and in vitro studies reveal that the acute administration of MDMA increases dopamine release (Johnson et al. 1986; Yamamoto and Spanos 1988; Gough et al. 1991; White et al. 1994). The augmented increase in extracellular dopamine observed in the nucleus accumbens after an MDMA injection in rats pretreated with repeated MDMA injections is akin to what has been previously shown for other amphetamine derivatives and cocaine (Robinson et al. 1988; Pettit et al. 1990; Kalivas and Duffy 1993; Wolf et al. 1993; Paulson and Robinson 1995; Heidbreder et al. 1996). Contrasting this resemblance between repeated MDMA and other commonly abused amphetamine derivatives, the acute increase in extracellular dopamine by MDMA is attenuated by blocking serotonin transporters with serotonin uptake inhibitors or pretreating animals with $5-\mathrm{HT}_{2}$ receptor antagonists (Yamamoto et al. 1995; Schmidt et al. 1994; Gudelsky and Nash 1996).

Considering the importance of serotonin in the acute effects of MDMA and the well-established toxic effect on serotonin-containing axons (O'Hearn et al. 1988; Wilson et al. 1989), one might expect that MDMAinduced increased dopamine transmission would be reduced after repeated MDMA injections. However, the extent of serotonin depletion is apparently not sufficient to impact the expression of sensitization, because Table 2 shows that both a neurotoxic $(20 \mathrm{mg} / \mathrm{kg}$, SC) 
and nonneurotoxic (5 mg/ $\mathrm{kg}, \mathrm{SC}$ ) repeated MDMA dosing regimen elicited behavioral sensitization. In support of this conclusion, Gartside et al. (1996) observed that in spite of significant tissue depletion of serotonin, a neurotoxic regimen of MDMA did not alter basal extracellular levels of serotonin in the hippocampus or frontal cortex. Although this indicates that sufficient serotonin transmission may remain to support sensitized behavioral activity and dopamine release, fenfluramine-evoked increases in extracellular serotonin are blunted in rats pretreated with a neurotoxic regimen of MDMA (Series et al. 1994). Alternatively, it is possible that the actions of MDMA in the nucleus accumbens may be relatively less dependent upon serotonin transmission, especially after repeated MDMA administration. Callaway and Geyer (1992) found that MDMA microinjection into the nucleus accumbens elicits an increase in motor activity that is not blocked by fluoxetine, which led these authors to conclude that "the behavioral effects of S-MDMA in the nucleus accumbens may result from the catecholamine-releasing properties that S-MDMA shares with S-amphetamine." Taken together with the present findings, it is possible that the augmented capacity of systemic MDMA to elevate extracellular dopamine in the nucleus accumbens may, in part, contribute to the sensitized behavioral response elicited by repeated MDMA treatment. In future studies, it will be important to determine if, in contrast to the acute response, the sensitized behavioral response to MDMA is blocked by dopamine receptor antagonists.

\section{Cross-Sensitization with Cocaine}

The behavioral stimulant effect of cocaine was augmented in the group of rats that were pretreated with the highest dose of repeated MDMA. This is akin to the behavioral cross-sensitization previously reported between amphetamine and repeated MDMA injections (Callaway and Geyer 1992). The cross-sensitization among repeated MDMA, amphetamine, and cocaine highlights possible overlap in the neural adaptations mediating behavioral sensitization. Indeed, akin to MDMA, behavioral sensitization to cocaine is generally associated with augmented dopamine release in the nucleus accumbens (Pettit et al. 1990; Kalivas and Duffy 1993; Heidbreder et al. 1996). However, in contrast to this similarity, repeated cocaine is associated with enhanced responsiveness of spiny cells in the nucleus accumbens to iontophoretic application of dopamine $\mathrm{D}_{1}$ receptor agonist (Henry and White 1991), whereas repeated MDMA produces an enduring reduction in the response to $D_{1}$ stimulation (White et al. 1996). Thus, although enhanced presynaptic transmission is a common neural adaptation produced by repeated cocaine, amphetamine, and MDMA, the effect of repeated drug treatment on dopamine postsynaptic responsiveness to dopamine is not a shared adaptation.

\section{CONCLUSIONS}

These data show that behavioral sensitization, as well as augmented dopamine transmission in the nucleus accumbens is produced by repeated MDMA administration in rats. This is akin to what is evoked by repeated injection of other amphetamine derivatives and cocaine and demonstrates the possibility of parallel neuroadaptations following the abuse of MDMA and amphetamines. Because the induction of behavioral and neurochemical sensitization in rodents is an animal model of amphetamine-induced psychosis and paranoia, the capacity of MDMA to elicit sensitization in rats supports the anecdotal literature (for review, see Green et al. 1995) that has documented the development of paranoia and psychosis in a subpopulation of individuals abusing MDMA.

\section{ACKNOWLEDGMENTS}

We thank Jenny Baylon for assistance in preparing the manuscript. The research was supported in part by USPHS grants \#DA-08116 (SRW), \#DA-03906 and \#MH-40817, and by a Research Career Development Award \#DA-00158.

\section{REFERENCES}

Akimoto K, Hamamura T, Kazahaya Y, Akiyama K, Otsuki S (1990): Enhanced extracellular dopamine level may be the fundamental neuropharmacological basis of crossbehavioral sensitization between methamphetamine and cocaine-An in vivo dialysis study in freely moving rats. Brain Res 507:344-346

Antelman SM (1988): Stressor-induced sensitization to subsequent stress: Implications for the development and treatment of clinical disorders. In Kalivas PW, Barnes CD (eds), Sensitization in the Nervous System. Caldwell, NJ, Telford Press, pp 227-256

Beardsley PM, Balster RL, Harris LS (1986): Self-administration of methylenedioxymethamphetamine (MDMA) by rhesus monkeys. Drug Alcohol Depend 18:149-157

Benzazzi F, Mazzoli M (1991): Psychiatric illness associated with "ecstasy." Lancet 388:1520

Bilsky EJ, Hui Y, Hubbell CL, Reid LD (1990): Methylenedioxymethamphetamine's capacity to establish place preferences and modify intake of an alcoholic beverage. Pharmacol Biochem Behav 37:633-638

Brady KT, Lydiard RB, Malcolm R, Ballenger JC (1991): Cocaine-induced psychosis. J Clin Psychiatry 52:509-512

Callaway CW, Geyer MA (1992): Stimulant effects of 3,4methylenedioxymethamphetamine in the nucleus accumbens of rat. Eur J Pharmacol 214:45-51 
Callaway CW, Wing LL, Geyer MA (1990): Serotonin release contributes to the locomotor stimulant effects of 3,4methylenedioxymethamphetamine in rats. J Pharmacol Exp Ther 254:456-464

Callaway CW, Johnson MP, Gold LH, Nichols DE, Geyer MA (1991): Amphetamines derivatives induce locomotor hyperactivity by acting as indirect serotonin agonists. Psychopharmacology 104:293-301

Callaway CW, Rempel N, Peng RY, Geyer MA (1992): Serotonin $5-\mathrm{HT}_{1}$-like receptors mediate hyperactivity in rats induced by 3,4-methylenedioxymethamphetamine. Neuropsychopharmacology 5:113-127

Creighton FJ, Black DL, Hyde CE (1991): Ecstasy psychosis and flashbacks. Br J Psychol 159:713-715

Cunningham KA, Paris JM, Goeders NE (1992): Serotonin neurotransmission in cocaine sensitization. Ann NY Acad Sci 654:117-127

Dafters RI (1995): Hyperthermia following MDMA administration in rats: Effects of ambient temperature, water consumption, and chronic dosing. Physiol Behav 5:877-882

Deutch AY, Tam S-Y, Roth RH (1985): Footshock and conditioned stress increase in 3,4-dihydroxyphenylacetic acid (DOPAC) in the ventral tegmental area but not substantia nigra. Brain Res 333:143-146

Ellinwood EH (1967): Amphetamine psychosis. I. Description of the individuals and process. J Nerv Ment Dis $144: 273-283$

Fitzgerald JL, Reid JJ (1990): Effects of methylenedioxymethamphetamine on the release of monoamines from rat brain slices. Eur J Pharmacol 191:217-220

Gartside SE, McQuade R, Sharp T (1996): Effects of repeated administration of 3,4-methylenedioxymethamphetamine on 5-hydroxytryptamine neuronal activity and release in the rat brain in vivo. J Pharmacol Exp Ther 279:277-283

Geyer MA (1996): Serotonergic functions in arousal and motor activity. Behav Brain Res 73:31-35

Gold LH, Koob GF (1989): MDMA produces stimulant-like conditioned locomotor activity. Psychopharmacology 99:352-356

Gough B, Ali SF, Slikker W Jr, Holson RR (1991): Acute Effects of 3,4-methylenedioxymethamphetamine (MDMA) on monoamines in rat caudate. Pharmacol Biochem Behav 39:619-623

Green AR, Cross AJ, Goodwin GM (1995): Review of the pharmacology and clinical pharmacology of 3,4-methylenedioxymethamphetamine (MDMA or "Ecstasy"). Psychopharmacology 119:247-260

Gudelsky GA, Nash JF (1996): Carrier-mediated release of serotonin by 3,4-methylenedioxymethamphetamine: Implications for serotonin-dopamine interactions. J Neurochem 66:243-249

Heidbreder CA, Thompson AC, Shippenberg TS (1996): Role of extracellular dopamine in the initiation and longterm expression of behavioral sensitization to cocaine. J Pharmacol Exp Ther 278:490-502

Henry DJ, White FJ (1991): Repeated cocaine administration causes persistent enhancement of $D_{1}$ dopamine receptor sensitivity within the rat nucleus accumbens. J Pharmacol Exp Ther 258:882-890
Johnson MP, Hoffman AJ, Nichols DE (1986): Effects of enantiomers of MDA, MDMA and related analogues on $3 \mathrm{H}$-serotonin and $3 \mathrm{H}$-dopamine release from superfused rat brain slices. Eur J Pharmacol 132:269-276

Kalivas PW, Duffy P (1993): Time course of extracellular dopamine and behavioral sensitization to cocaine. I. Dopamine axon terminals. J Neurosci 13:266-275

Kalivas PW, Stewart J (1991): Dopamine transmission in the initiation and expression of drug- and stress-induced sensitization of motor activity. Brain Res Rev 16:223-244

Kalivas PW, Duffy P, DuMars LA, Skinner C (1988): Neurochemical and behavioral effects of acute and daily cocaine. J Pharmacol Exp Ther 245:485-492

Kolta MG, Shreve P, De Souza V, Uretsky NJ (1985): Time course of the development of the enhanced behavioral and biochemical responses to amphetamine after pretreatment with amphetamine. Neuropharmacology 24:823-829

Lamb RJ, Griffiths RR (1987): Self-injection of 3,4-methylenedioxymethamphetamine (MDMA) in the baboon. Psychopharmacology 91:268-272

Marona-Lewicka D, Rhee GS, Sprague JE, Nichols DE (1996): Reinforcing effects of certain serotonin-releasing amphetamine derivatives. Pharmacol Biochem Behav 53:99-105

McCann UD, Ricaurte GA (1991): Lasting neuropsychiatric sequelae of (+)-3,4-methylenedioxymethamphetamine ("ecstasy") in recreational users. J Clin Psychopharmacol 11:302-305

McNamara MG, Kelly JP, Leonard BE (1995): Some behavioural and neurochemical aspects of subacute $( \pm) 3,4-$ methylenedioxymethamphetamine administration in rats. Pharmacol Biochem Behav 52:479-484

Milliken GA, Johnson DE (1984): Analysis of Messy Data. Vol. I: Designed Experiments. Belmont, CA, Lifetime Learning Publications

Nash JF, Brodkin J (1991): Microdialysis studies on 3,4-methylenedioxymethamphetamine-induced dopamine release: Effect of dopamine uptake inhibitors. J Pharmacol Exp Ther 259:820-825

O’Hearn E, Battaglia G, DeSouza EB, Kuhar MJ, Molliver ME (1988): Methylenedioxyamphetamine (MDA) and methylenedioxymethamphetamine (MDMA) cause selective ablation of serotonergic axon terminals in forebrain: Immunocytochemical evidence for neurotoxicity. J Neurosci 8:2788-2803

Paulson PE, Robinson TE (1995): Amphetamine-induced time-dependent sensitization of dopamine neurotransmission in the dorsal and ventral striatum: A microdialysis study in behaving rats. Synapse 19:56-65

Paulson PE, Camp DM, Robinson TE (1991): Time course of transient behavioral depression and persistent behavioral sensitization in relation to regional brain monoamine concentrations during amphetamine withdrawal in rats. Psychopharmacology 103:480-492

Paxinos G, Watson C (1986): The Rat Brain in Stereotaxic Coordinates. New York, Academic Press

Pelligrino LK, Pellegrino AS, Cushman AJ (1979): A Stereotaxic Atlas of the Rat Brain. New York, Plenum Press

Pettit HO, Pan H-T, Parsons LH, Justice JB Jr (1990): Extracellular concentrations of cocaine and dopamine are 
enhanced during chronic cocaine administration. J Neurochem 55:798-804

Post RM (1975): Cocaine psychosis: A continuum model. J Psychiatry 132:225-231

Robinson TE, Becker JB (1986): Enduring changes in brain and behavior produced by chronic amphetamine administration: A review and evaluation of animal models of amphetamine psychosis. Brain Res Rev 11:157-198

Robinson TE, Wishaw IQ (1988): Normalization of extracellular dopamine in the striatum following recovery from a partial unilateral 6-OHDA lesion of the substantia nigra: A microdialysis study in freely moving rats. Brain Res 450:209-224

Robinson TE, Jurson PA, Bennett JA, Bentgen KM (1988): Persistent sensitization of dopamine neurotransmission in ventral striatum (nucleus accumbens) produced by prior experience with $(+)$-amphetamine: A microdialysis study in freely moving rats. Brain Res 462:211-222

Satel SL, Southwick SM, Gawin FH (1991): Clinical features of cocaine-induced paranoia. Am J Psychiatry 148:495-498

Schmidt CJ, Sullivan CK, Fadayel GM (1994): Blockade of striatal 5-hydroxytryptamine ${ }_{2}$ receptors reduces the increase in extracellular concentrations of dopamine produced by the amphetamine analogue 3,4-methylenedioxymethamphetamine. J Neurochem 62:1382-1389

Segal DS, Kuczenski R (1987): Individual differences in responsiveness to single and repeated amphetamine administration: Behavioral characteristics and neurochemical correlates. J Pharmacol Exp Ther 242:917-926

Segal DS, Schuckit MA (1983): Animal models of stimulantinduced psychosis. In Creese I (ed), Stimulants: Neurochemical, Behavioral, and Clinical Perspectives. New York, Raven Press, pp 131-167

Seiden LS, Sabol KE, Ricuarte GA (1993): Amphetamine: Effects on catecholamine systems and behavior. Annu Rev Pharmacol Toxicol 33:639-677

Series HG, Cowen PJ, Sharp T (1994): p-Chloroamphetamine (PCA), 3,4-methylenedioxymethamphetamine (MDMA) and d-fenfluramine pretreatment attenuates d-fenfluramine-evoked release of 5-HT in vivo. Psychopharmacology 116:508-514
Spanos LJ, Yamamoto BK (1989): Acute and subchronic effects of methylenedioxymethamphetamine [( \pm MDMA] on locomotion and serotonin syndrome behavior in the rat. Pharmacol Biochem Behav 32:835-840

Steele TD, McCann UD, Ricaurte GA (1994): 3,4-methylenedioxymethamphetamine (MDMA, "Ecstacy"): Pharmacology and toxicology in animals and humans. Addiction 89:539-551

Stewart J, Vezina P (1988): Conditioning and behavioral sensitization. In Kalivas PW, Barnes CD (eds), Sensitization in the Nervous System. Caldwell, NJ, Telford Press, pp 207-224

Whitaker-Azmitia PM, Aronson TA (1989): "Ecstacy" (MDMA)-induced panic. Am J Psychiatry 146:119

White SR, Duffy P, Kalivas PW (1994): Methylenedioxymethamphetamine depresses glutamate-evoked neuronal firing and increases extracellular levels of dopamine and serotonin in the nucleus accumbens in vivo. Neuroscience $62: 41-50$

White SR, Obradovic T, Imel KM, Wheaton MJ (1996): The effects of methylenedioxymethamphetamine (MDMA, "ecstacy") on monoaminergic neurotransmission in the central nervous system. Prog Neurobiol 49:455-479

Wilson MA, Ricaurte GA, Molliver ME (1989): Distinct morphologic classes of serotonergic axons in primates exhibit differential vulnerability to the psychotropic drug, 3,4-methylenedioxymethamphetamine. Neuroscience 28:121-137

Wolf ME, White FJ, Nassar R, Brooderson RJ, Khansa MR (1993): Differential development of autoreceptor subsensitivity and enhanced dopamine release during amphetamine sensitization. J Pharmacol Exp Ther 264:249-255

Yamamoto BK, Spanos LJ (1988): The acute effects of methylenedioxymethamphetamine on dopamine release in the awake-behaving rat. Eur J Pharmacol 148:195-203

Yamamoto BK, Nash JF, Gudelsky GA (1995): Modulation of methylenedioxymethamphetamine-induced striatal dopamine release by the interaction between serotonin and g-aminobutyric acid in the substantia nigra. J Pharmacol Exp Ther 273:1063-1070 